\title{
Investigation of Methylation Status of Homeobox D3 (HOXD3) and Protocadherin 17 (PCDH17) in Patients with Prostate Cancer
}

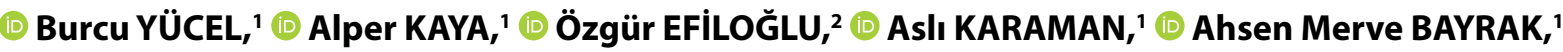 \\ (D) Hatice IKIIIŞIK, 3 (D) Asıf YILDIRIM, ${ }^{2}$ (D) Berna DEMIRCAN'
}

'Department of Medical Biology, Istanbul Medeniyet University, Istanbul-Turkey

${ }^{2}$ Department of Urology, Istanbul Medeniyet University, Istanbul-Turkey

${ }^{3}$ Department of Public Health, Istanbul Medeniyet University, Istanbul-Turkey

\begin{abstract}
OBJECTIVE
Prostate cancer is one of the most common cancers in male gender. Despite recent advances in the diagnosis and the treatment methods, more reliable molecular biomarkers have been needed for the diagnosis and evaluation of response to treatments such as chemotherapy, anti-androgen therapy, and radiotherapy. The aim of this study is to investigate promoter methylation status of HOX3D and PCDH17 genes in prostate cancer in Turkish population.
\end{abstract}

\section{METHODS}

A total of 46 patients with prostate cancer were included in this study. Tissue samples obtained from 36 patients with benign prostate hyperplasia were used as controls. Methylation status of HOXD3 and PCDH17 genes was determined by quantitative Methylation-Specific PCR with commercially available primer sets.

\section{RESULTS}

Both HOXD3 and PCDH17 promoter methylation was determined significantly higher in patients with compare to controls $(\mathrm{p}=0.0198$ and $\mathrm{p}=0.0386$, respectively). A significant but weak correlation was found between methylation status and pre-operative PSA level for HOXD3 (Spearman's rho $=0.259$, $\mathrm{p}=0.02$ ) and PCDH17 gene (Spearman's rho $=0.324, \mathrm{p}=0.006$ ).

\section{CONCLUSION}

Our results indicated that HOXD3 and PCDH17 promoter methylation levels are higher in patients with prostate cancer. Further studies with large sample cohorts and clinicopathological data will enlighten presumptive role of HOXD3 and PCDH17 methylation status.

Keywords: HOXD3; PCDH17; methylation; prostate cancer.

Copyright $\odot$ 2021, Turkish Society for Radiation Oncology

\section{Introduction}

Prostate cancer ranks second after lung cancer in cancer-related deaths in men.[1] Prostate cancer exhibits geographic variation in incidence and mortality.[2]
In America and European countries, these rates are quite high compared to Asian and African countries. [3] The most commonly used methods for diagnosis are measurement of serum PSA levels and pathological examination of biopsy samples. The most encountered 
problem in determining the disease with biopsy is "blind biopsies." As a result of the biopsies taken without using the imaging method, the cancerous area may be completely overlooked and false negative results can be obtained.[4] Measurement of PSA levels is another method used in the diagnosis of the disease, predicting the response to treatment and determining the risk of recurrence.[5] However, its clinical use is controversial due to insufficient sensitivity, specificity, and predictive values of PSA levels. It has the potential to lead to misdiagnosis and unnecessary treatment. Another drawback of using PSA levels in diagnosis and prognosis is that the PSA is the androgen receptor target gene. Therefore, in patients receiving anti-androgen therapy, androgen receptor signal will be down-regulated and PSA expression will be decreased. In this regard, it is unclear whether the decrease in PSA level is due to the decrease in the number of cancerous cells or the decrease in PSA expression as a result of the treatment.[6] In addition, it has been determined that a large number of compounds that do not have antitumor activity can modulate PSA expression.[7] For all these reasons, much more reliable molecular biomarkers have been needed for diagnosis and evaluation of response to treatments such as chemotherapy, anti-androgen therapy, radiotherapy, or combinational multimodal therapy depending on the disease stage.[8] Serial monitoring is applied for localized prostate cancer, whereas in addition to surgery, radiation therapy is used for patients with locally advanced prostate cancer.[4] Abiraterone and enzalutamide are recent chemotherapeutics that can improve prognosis in metastatic prostate cancer patients, especially in those are resistant to traditional hormonal therapy.[7]

Epigenetics are the alterations in gene expression without changing the primary DNA sequence. One of the epigenetic modifications that cause this change is DNA methylation. It occurs by adding methyl groups to the $\mathrm{CpG}$ dinucleotides in the genome by the DNA methyl transferase enzyme. Hypermethylation of CpG dinucleotides located in the promoter regions of genes is an epigenetic modification that can cause genes to be silenced. While one allele of the gene is inactivated by genetic mechanisms such as point mutation or deletion, methylation of CpG islands in promoters can inactivate the other allele (Knudson's two-hit hypothesis).[9] Mostly tumor suppressor genes are silenced as a result of these mechanisms. Inactivation by hypermethylation has been detected in genes encoding proteins involved in prostate cancer, cell cycle checkpoints, DNA repair, invasion, and metastasis, as in many types of cancer.[10] It is believed that DNA hypermethylation occurs early in tumor formation and plays a major role in tumor initiation and prognosis. [11] In the literature, it has been shown that hundreds of genes are silenced by promoter DNA methylation in a coordinated manner in methylation studies conducted especially with solid tumors and covering the whole genome. In addition, it is stated that there are tumor-specific methylation models.[12] Similar to genetic changes, epigenetic changes are also inherited and stable. Therefore, they have the potential to be used as a molecular biomarker in cancer patients for early diagnosis, prognosis, and prediction of response to treatment.[13] In studies conducted for this purpose, genes that can be used as biomarkers in prostate cancer have been investigated. Genes with high sensitivity and specificity in prostate cancer have been investigated in single gene studies and gene panels studies and it has been reported that many genes have the potential to become biomarkers through promoter DNA hypermethylation.[10]

In this study, we aimed to investigate promoter methylation status of HOX3D and PCDH17 tumor suppressor genes in prostate cancer in Turkish population. HOXD3 gene is a member of homeobox gene family of transcription factors. Altered expression of many homeobox genes have been found different tumors including prostate cancer.[14] PCDH17 gene belongs to protocadherin gene family and its methylation level is suggested to be important in tumor progression for several cancers.[15] Depending on the treatment received by the patients, these two genes could be important in the diagnosis and evaluation of response to treatment of prostate cancer. Our study will contribute to intensive studies on the use of tumor suppressor genes as molecular biomarkers in the diagnosis and prognosis of prostate cancer.

\section{Materials and Methods}

\section{Sample Collection}

This study was approved by Istanbul Medeniyet University Goztepe Training and Research Hospital Ethical committee with decision number 2017/0257. A total of 46 prostate tumor samples and 36 non-tumoral (benign) prostate tissue samples were used for this study. Prostate tumor samples were obtained from prostate cancer patients who had operation of radical prostatectomy. Non-tumoral prostate tissues were obtained from patients with benign prostatic hyperplasia. Tumor and non-tumor samples were confirmed with pathology results. 


\section{DNA Isolation}

Genomic DNA isolation was performed using Invitrogen PureLink Genomic DNA kits using $25 \mathrm{mg}$ of tissue for each sample in accordance with the manufacturer's instructions. For each sample, $25 \mathrm{mg}$ of prostate tissue was incubated mixed with 180 ul PureLink genomic digestion buffer and $20 \mathrm{ul}$ proteinase $\mathrm{K}$ in $55^{\circ} \mathrm{C}$ for 4 $\mathrm{h}$ to overnight. The resulting lysate was centrifuged at full speed for $3 \mathrm{~min}$ and the sediments were removed. 20 ul RNAase A was added and incubated at room temperature for $2 \mathrm{~min}$. $200 \mathrm{ul}$ genomic binding/lysis buffer was added and homogenized with vortex, then $200 \mathrm{ul}$ 96-100\% ethanol was added and vortexed again. The lysate with a final volume of approximately $640 \mathrm{ul}$ was added to the spin column and centrifuged for $1 \mathrm{~min}$ at $10000 \mathrm{~g}$. The fluid that went under the membrane was discarded. 500 ul wash buffer 1 was added to the spin column, centrifuged at $10000 \mathrm{~g}$ for $1 \mathrm{~min}$ and the liquid underneath was discarded, 500 ul wash buffer 2 was added to the column, 3 min after centrifuge at maximum speed, the liquid that passed below was discarded. The spin column was placed in a $1.5 \mathrm{ml}$ tube, elution with $40 \mathrm{ul}$ PureLink genomic elution buffer was performed with the help of centrifuge. DNA concentration and purity parameters were evaluated by nanodrop.

\section{Methylation Analysis}

Methylation analysis was performed in accordance with manufacturer's instructions using Qiagen Epitect Methyl II PCR assay kits. For each sample, 125 ng genomic DNA was mixed with $13 \mathrm{ul}$ restriction digestion buffer up to $60 \mathrm{ul}$ final volume with varying amounts of water, and vortexed. This prepared mix was taken 14 $\mathrm{ul}$ at a time and distributed in 4 separate tubes. Enzyme reaction tubes of four different contents were created by placing $1 \mathrm{ul}$ water in the first of these four tubes,
$0.5 \mathrm{ul}$ methylation sensitive enzyme A and $0.5 \mathrm{ul}$ water in the second, $0.5 \mathrm{ul}$ methylation dependent enzyme $\mathrm{B}$ and $0.5 \mathrm{ul}$ water in the third, and $0.5 \mathrm{ul}$ of each enzyme $A$ and enzyme $B$ in the fourth tube. Thus, the first tube was an enzyme-free mock tube, the second tube contained only enzyme A Ms (methylation sensitive), the third tube contained only enzyme B Md (methylation dependent), and the fourth tube was Msd (sensitive and dependent) creating 4 reaction tubes with a total volume of $15 \mathrm{ul}$ each. Each tube was incubated at $37^{\circ} \mathrm{C}$ for $6 \mathrm{~h}$ and digestion reaction was performed, then the tubes were incubated at $65^{\circ} \mathrm{C}$ at $20 \mathrm{~min}$ to stop the enzyme activity and then stored at -20 degrees for later use in the real time PCR stage.

The qPCR reaction was established with a total volume of $10 \mathrm{ul}$ and with 36 tubes plate in the Qiagen rotor gene $\mathrm{q}$ device. The reaction was established with $5 \mathrm{ul} \mathrm{Qi}-$ agen SYBR green, 0.4 ul Qiagen primary mix (HOXD3 and PCDH17), 2 ul digestion reaction material prepared in the previous stage and $2.6 \mathrm{ul}$ water. For each primer, 4 tubes were created with the final volume of $10 \mathrm{ul}$ for each gene and each sample ; Mo, Ms, Md, Msd, accordingly Mock, enzyme A, enzyme B, and enzyme A+B. qPCR protocol was set to be $95^{\circ} \mathrm{C} 10 \mathrm{~min} 1 \mathrm{cycle}, 99^{\circ} \mathrm{C} 30 \mathrm{~s}$ and $72^{\circ} \mathrm{C} 1 \mathrm{~min} 3 \mathrm{cycle}, 97^{\circ} \mathrm{C} 15 \mathrm{~s}$ and $72^{\circ} \mathrm{C} 1 \mathrm{~min}$ (SYBR reading) 40 cycles in accordance with manufacturer's guidelines, and a melt curve analysis protocol was added. To get reliable results, qPCR reactions were performed in duplicates for each tube, for total of two different gene regions and for each sample examined for methylation. Mo, Ms, Md, and Msd qPCR Ct results were exported to Microsoft Excel from Qiagen rotor gene q 2.1.0.9 software with the threshold value of 0.01 for each reading (Supplemental Fig. 1). CT data for each 4 tubes of each sample and each primer were arranged and appropriately applied into the Epitect Methyl II qPCR primary data analysis Microsoft Excel worksheet, which per-

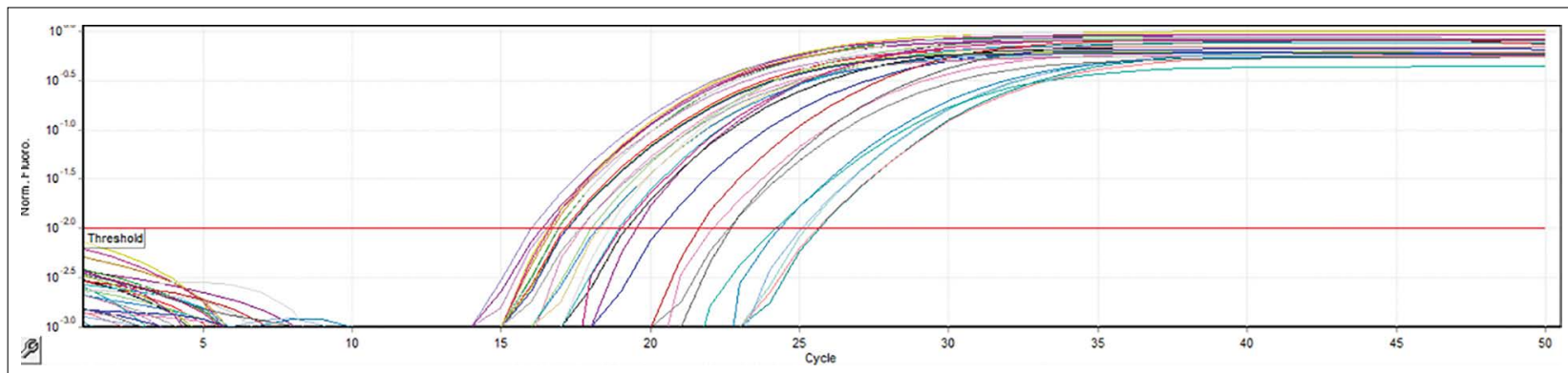

Suppl. Fig. 1. A representative image of Real-Time PCR results before analysis. Ct values were calculated as described in materials and methods.

PCR: Polymerase Chain Reaction; Ct: Cycle threshold. 
forms methylation analysis for the specific gene region by comparing Mo, Ms, Md, and Msd CT values through specific equations and was specially prepared by Qiagen for the kit, then the results of methylation rates were obtained. Provided by Qiagen, this worksheet was a tool that automatically performs the calculations that the manufacturer had already provided in the kit manual. After the methylation percentages were determined for each sample and each gene region, the necessary statistical analysis was performed.

\section{Statistical Analysis}

Differences in gene promoter methylation levels between prostate cancer patients and controls were analyzed and graphs were obtained in GraphPad Prism V7 program (San Diego, CA, USA) using Student's t test. For epidemiological data analysis, Statistical Package for Social Sciences (SPSS) for Windows 22.0 (SPSS Inc., Chicago, Ill., USA) was used. The study data were shown as mean and standard deviation as data fit the normal distribution by Kolmogorov-Smirnov test. Spearman's correlation test was applied for correlation analysis. A $\mathrm{p}<0.05$ was accepted as significant.

\section{Results}

\section{Study Population}

Patients demographics and clinical data are given in Tables 1 and 2. Gleason Scores and ISUP Grades are given in Tables 3 and 4 . Total 46 prostate tumor and 36 control DNA samples were used for methylation analysis due to failure in qPCR reaction as a result of low DNA quality or amount of samples.

\section{HOXD3 Promoter Methylation}

HOXD3 promoter methylation level was determined using real-time prob-based PCR analysis (qMSP). HOXD3 promoter was found $57.8 \%$ methylated $(42.11 \%$ unmethylated) in patients while the methylation level was $43.06 \%$ (56.93\% unmethylated) in the control group. As compared to the controls, HOXD3 promoter methylation was detected significantly higher in prostate cancer patients ( $\mathrm{p}=0.0198$ ) (Fig. 1 and Table 5).

\section{PCDH17 Promoter Methylation}

PCDH17 promoter methylation level was also detected using the same qMSP protocol. Mean methylation level was calculated as $37.22 \%$ (62.77\% unmethylated) in patients with prostate cancer. In the control group, methylation level was determined as $23.04 \%$ (76.95\% unmethylated). PCDH17 methylation was detected

Table 1 Characteristics of the study population

\begin{tabular}{lc} 
Characteristic & Mean \pm SD \\
\hline Age & $67.17 \pm 7.57$ \\
Height & $170.86 \pm 5.33$ \\
Weight & $78.46 \pm 10.60$ \\
BMI & $26.83 \pm 3.15$ \\
Age at diagnosis & $67.00 \pm 7.39$ \\
PSA & $14.31 \pm 29.40$ \\
Smoking pack/year & $26.2 \pm 17.5$ \\
\hline
\end{tabular}

BMI: Body mass index; PSA: Prostate-specific antigen

Table 2 Clinicopathological characteristics of patients $(n=46)$

\begin{tabular}{|c|c|c|}
\hline Characteristic & $\mathbf{n}$ & $\%$ \\
\hline \multicolumn{3}{|l|}{ Smoking $(n=46)$} \\
\hline None & 8 & 17.39 \\
\hline$<20$ & 15 & 32.60 \\
\hline $20<$ & 23 & 50 \\
\hline \multicolumn{3}{|l|}{ Family history $(\mathrm{n}=46)$} \\
\hline No & 40 & 86.95 \\
\hline Yes & 6 & 13.04 \\
\hline \multicolumn{3}{|l|}{ Comorbidity $(n=46)$} \\
\hline No & 12 & 26.08 \\
\hline Yes & 34 & 73.91 \\
\hline \multicolumn{3}{|l|}{ High Blood Pressure } \\
\hline Yes & 21 & 45.65 \\
\hline \multicolumn{3}{|l|}{ Diabetes Mellitus } \\
\hline Yes & 10 & 21.73 \\
\hline \multicolumn{3}{|c|}{ Chronic obstructive pulmonary disease } \\
\hline Yes & 2 & 4.34 \\
\hline \multicolumn{3}{|l|}{ Hypothyroidism } \\
\hline Yes & 3 & 6.52 \\
\hline \multicolumn{3}{|l|}{ Diagnosis Stage $(n=46)$} \\
\hline Localized psa T1-2 & 38 & 82.60 \\
\hline Locally advanced psa T3-4 & 6 & 13.04 \\
\hline Metastatic pca $\mathrm{N}+$ and/or $\mathrm{M}+$ & 2 & 4.34 \\
\hline \multicolumn{3}{|l|}{ Recent stage $(n=46)$} \\
\hline Localized pca & 36 & 78.26 \\
\hline Locally advanced pca & 7 & 15.21 \\
\hline Metastatic pca & 3 & 6.52 \\
\hline \multicolumn{3}{|l|}{ Biochemical } \\
\hline \multicolumn{3}{|l|}{ Recurrence $(n=46)$} \\
\hline Yes & 10 & 21.73 \\
\hline No & 36 & 78.26 \\
\hline \multicolumn{3}{|l|}{ Progression $(n=46)$} \\
\hline Yes & 3 & 6.52 \\
\hline No & 43 & 93.47 \\
\hline
\end{tabular}

psa: Prostate-specific antigen; pca: Prostate cancer 


\begin{tabular}{lcc} 
Table 3 & Gleason Scores of prostate cancer patients \\
\hline Gleason Score $(\mathbf{n}=\mathbf{4 6})$ & $\mathbf{n}$ & $\%$ \\
\hline $3+3$ & 9 & 19.56 \\
$3+4$ & 15 & 32.60 \\
$4+3$ & 9 & 19.56 \\
$4+4$ & 6 & 13.04 \\
$4+5$ & 6 & 13.04 \\
NA & 1 & 2.17 \\
\hline
\end{tabular}

NA: Not available

Table 4 ISUP Grades of prostate cancer patients

\begin{tabular}{lcc} 
ISUP Grade $(\mathbf{n = 4 6 )}$ & $\mathbf{n}$ & \% \\
\hline 1 & 9 & 19.56 \\
2 & 15 & 32.60 \\
3 & 9 & 19.56 \\
4 & 6 & 13.04 \\
5 & 6 & 13.04 \\
NA & 1 & 2.17 \\
\hline
\end{tabular}

ISUP: International Society of Urological Pathology; NA: Not available

higher in the patients as compared to the control group and this difference was statistically significant $(\mathrm{p}=0.0386)$ (Fig. 2 and Table 6).

\section{Promoter Methylation and PSA Level}

To analyze prognostic significance of HOXD3 and PCDH17 gene promoter methylation levels in prostate cancer, correlation analysis was applied to seek for association of methylation status and PSA level. A week but positive correlation was found for HOXD3 (Spearman's rho=0.259, $\mathrm{p}=0.02$ ) and PCDH17 gene methylation (Spearman's rho $=0.324, \mathrm{p}=0.006$ ) and PSA levels of patients. It appears that increase in methylation status of genes associated with elevated PSA level (Fig. 3).

\section{Discussion}

Prostate cancer is one of the most common cancer especially in elderly men.[3] Most of the prostate tumors can be detected at the local stage and cured by radical prostatectomy. However, a large number of patients have biochemical recurrence or develop metastatic cancer.[7] Prostate cancer is a heterogenous disease as other cancer types and scientist have applied multiple approaches to develop reliable, novel detection methods.[16] Aberrant DNA methylation have been shown to play important roles in cancer development and pro-

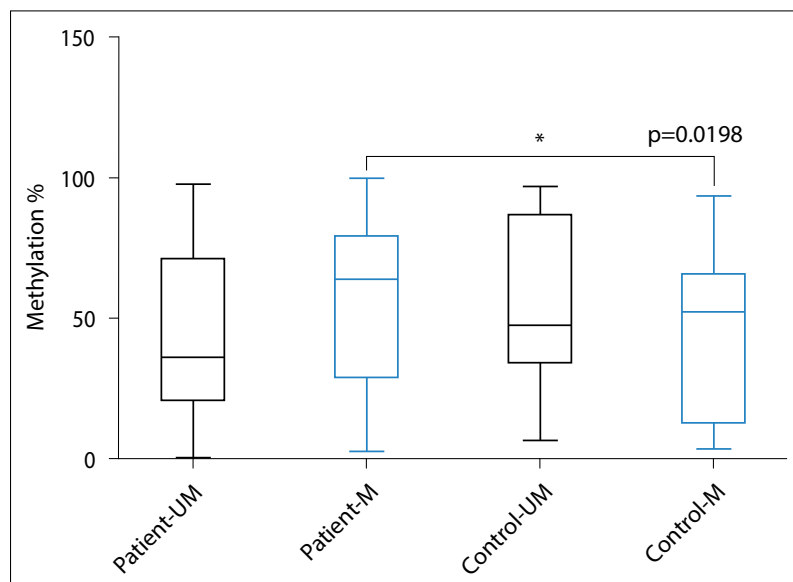

Fig. 1. HOXD3 promoter methylation level in prostate cancer patients and in control group. Data presented as mean \pm Standart Deviation (SD). HOXD3: Homeobox D3, UM: Unmetile, M: Metile.

Table 5 HOXD3 promoter methylation levels in prostate cancer patients and controls

\begin{tabular}{lllllll} 
& \multicolumn{2}{c}{$\begin{array}{c}\text { Patients } \\
(\mathbf{n}=\mathbf{4 6})\end{array}$} & & \multicolumn{2}{c}{$\begin{array}{c}\text { Control } \\
(\mathbf{n}=\mathbf{3 6})\end{array}$} \\
\cline { 2 - 3 } Gene & UM & $\mathbf{M}$ & & UM & $\mathbf{M}$ & $\mathbf{p}$ \\
\hline HOXD3, \% & 42.11 & 57.80 & 56.93 & 43.06 & 0.0198 \\
\hline
\end{tabular}

HOXD3: Homeobox D3; UM: Unmethylated; M: Methylated

gression.[9] Determination of DNA methylation has been suggested to involve in the development of diagnostic biomarkers as well as identification of therapeutic targets.[10] In addition to PSA detection, methylation status of several genes either individually or in combination has been studied in prostate cancer to discover reliable biomarkers in the diagnosis of the disease.[17]

In this study, we determined the promoter methylation of HOXD3 and PCDH17 genes by quantitative Methylation-Specific PCR (qMSP). HOXD3 is a member of Homeobox genes and they are a family of transcription factors. [18] Methylation of homeobox genes has been determined as a common event in prostate cancer and especially methylation of HOXD3 gene have been shown to promote gene silencing.[19] The relationship between HOXD3 methylation and prognosis of prostate cancer has been previously determined. HOXD3 methylation has been found significantly increased in patients with higher Gleason score, an indicator of disease progression. [20] This data proposed that HOXD3 methylation level might have a 


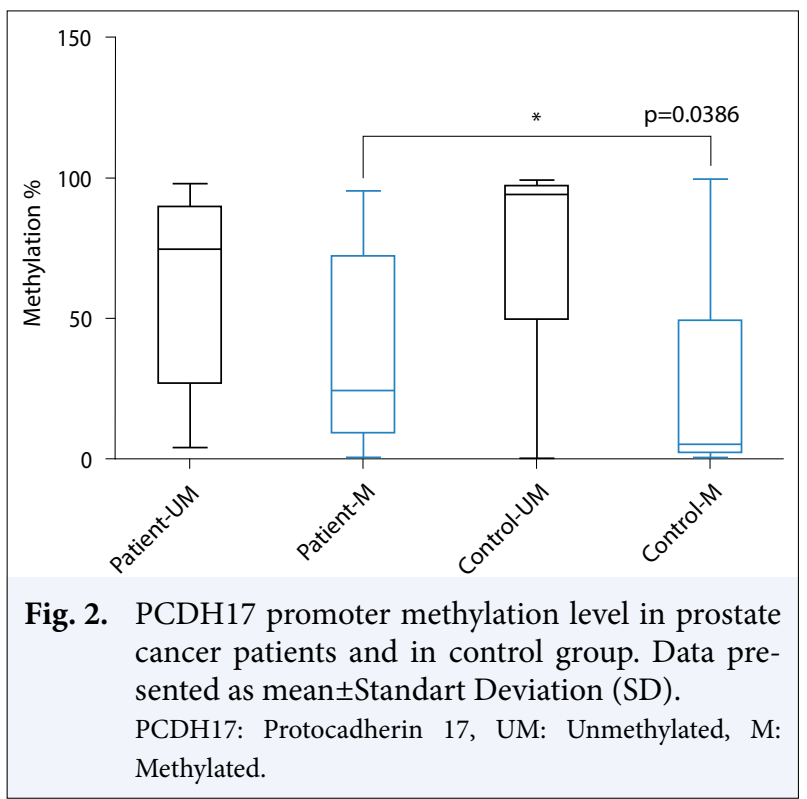

Table 6 Mean promoter methylation levels in prostate cancer patients and controls

\begin{tabular}{lcccccc} 
& \multicolumn{2}{c}{$\begin{array}{c}\text { Patients } \\
(\mathbf{n}=\mathbf{4 6})\end{array}$} & & \multicolumn{2}{c}{$\begin{array}{c}\text { Control } \\
(\mathbf{n}=\mathbf{3 6})\end{array}$} \\
\cline { 2 - 3 } Gene & UM & $\mathbf{M}$ & & UM & $\mathbf{M}$ & $\mathbf{p}$ \\
\hline PCDH17, \% & 62.77 & 37.22 & & 76.95 & 23.04 & 0.0386 \\
\hline
\end{tabular}

PCDH17: Protocadherin 17; UM: Unmethylated; M: Methylated

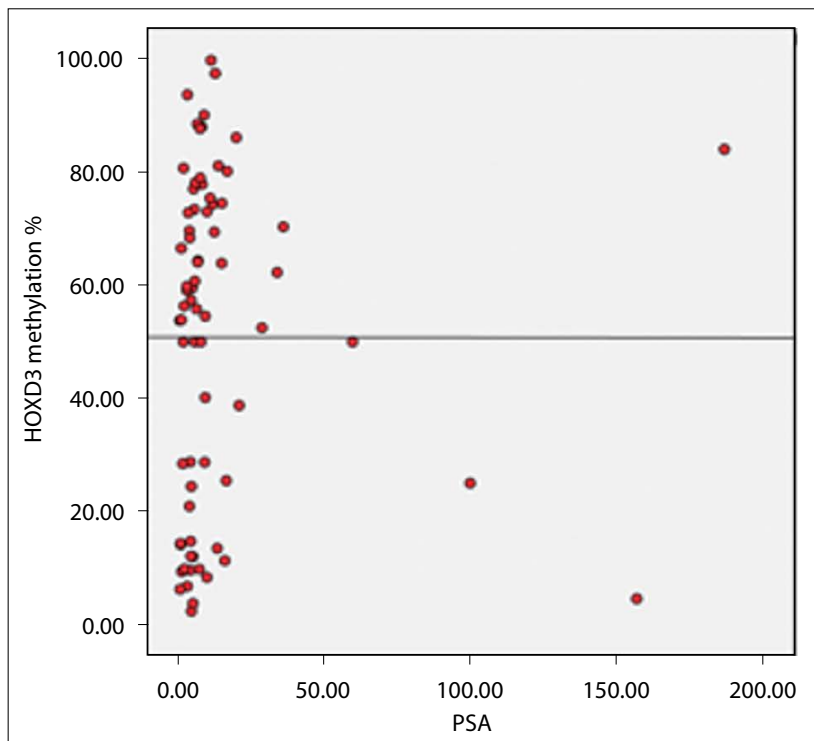

prognostic value. In addition to individual methylation status, HOXD3 was combined with TGF- $\beta$, RASSF1A and APC genes to identify a panel of epigenetic markers.[21] It was found that the presence of high methylation levels in two or more genes mentioned above might predict biochemical recurrence.[21] In another study, CRIP3 gene methylation was analyzed together with HOXD3, TGF- $\beta$, and APC genes. Similar to our study, qMSP was applied to determine methylation status.[22] It was found that when combined with PSA level at diagnosis, methylation status of this gene panel might be indicator of biochemical recurrence.[22] In our study, we determined that HOXD3 methylation level was significantly higher in patients with prostate cancer as compared to healthy controls.

Recently, cadherin protein superfamily gained much attraction by scientist in cancer research. Expression of classical cadherins, protocadherins ( $\mathrm{PCDH})$ and cadherin-related proteins have been associated with various steps in cancer development and progression. [23] PCDHs are located on chromosome 13q21.2 and their downregulation due to promoter methylation has been determined in various cancer types.[15] PCDH17, a member of PCDHs, have been identified as a tumor suppressor gene and it is often found inactivated by promoter methylation in different tumors, including laryngeal squamous cell carcinoma,[24] urothelial carcinomas,[25] bladder cancer,[26] gastric, and colorectal cancers.[27] In patients with prostate cancer,

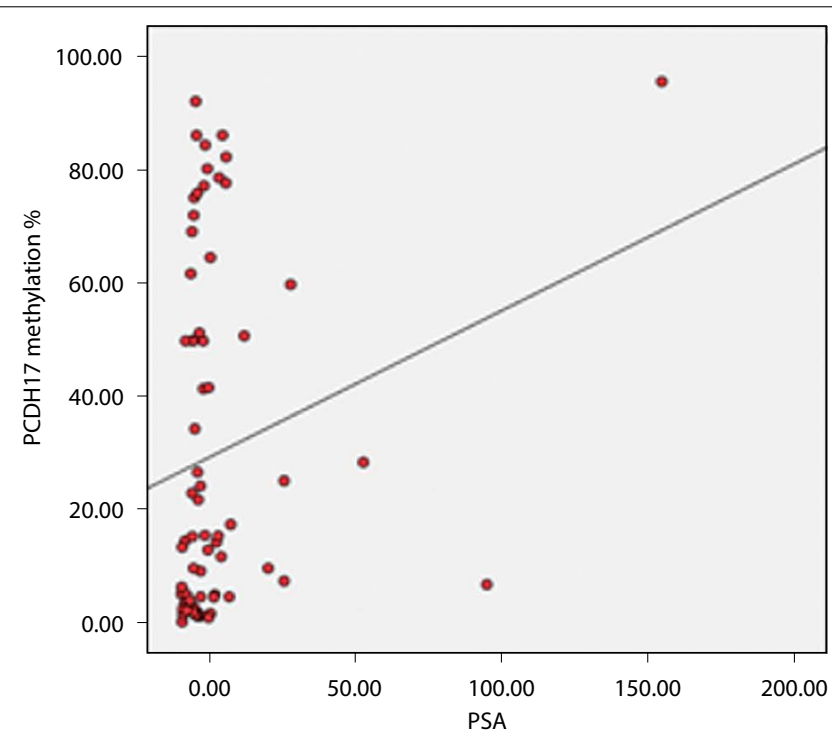

Fig. 3. Correlation of HOXD3 and PCDH17 promoter methylation and PSA level in prostate cancer patients. $\mathrm{R}^{2}=5.266 \mathrm{E}-7$ and 0.040 , respectively.

HOXD3: Homeobox D3; PCDH17: Protocadherin 17; PSA: Prostate-specific antigen. 
regarding to its clinical significance, it was shown that methylation of PCDH17 is significantly associated with higher Gleason score, advance pathological stage and high level of pre-operative PSA level.[28]

In this study, PCDH17 methylation level was also determined significantly higher in patients with prostate cancer compared to controls. Furthermore, both HOXD3 and PCDH17 promoter methylation showed significant but weak correlation with pre-operative PSA level. This weak correlation could be explained by the small number of our study group. This was the limitation of our study. In addition, among our study group, we had clinicopathological parameters for fewer patients, which prevented us to obtain substantial data on prognostic value of HOXD3 and PCDH17 genes.

To conclude, in compliance with the literature, our results showed that HOXD3 and PCDH17 promoter methylation levels are higher in patients with prostate cancer. Further studies with large sample cohorts and clinicopathological data will enlighten presumptive role of HOXD3 and PCDH17 methylation in development of novel diagnostic and prognostic markers in prostate cancer.

Acknowledgment: This study is funded by Istanbul Medeniyet University Scientific Research Fund (T-GAP-20181344-BAP), grant no: T-GAP-2018-1344.

Peer-review: Externally peer-reviewed.

Conflict of Interest: All authors declared no conflict of interest.

Ethics Committee Approval: The study was approved by the Istanbul Medeniyet University Goztepe Training and Research Hospital Clinical Research Ethics Committee (No: 2017/0257, Date: 24/08/2017).

Financial Support: Istanbul Medeniyet University BAP (TGAP-2018-1344).

Authorship contributions: Concept - B.Y.; Design - B.Y., B.D.; Supervision - B.Y.; Funding - B.Y.; Materials - Ö.E., A.Y.; Data collection and/or processing - A.Kaya, A.K., A.M.B., H.I..; Data analysis and/or interpretation - B.Y.; Literature search - B.Y.; Writing - B.Y., A.K.; Critical review B.Y., B.D.

\section{References}

1. Rawla P. Epidemiology of prostate cancer. World J Oncol 2019;10(2):63-89.

2. Culp MB, Soerjomataram I, Efstathiou JA, Bray F, Jemal A. Recent global patterns in prostate cancer incidence and mortality rates. Eur Urol 2020;77(1):38-52.
3. Pernar CH, Ebot EM, Wilson KM, Mucci LA. The epidemiology of prostate cancer. Harb Cold Spring Perspect Med 2018;8(12):a030361.

4. Litwin MS, Tan HJ. The diagnosis and treatment of prostate cancer: A review. JAMA 2017;317(24):253242.

5. Tikkinen KA, Dahm P, Lytvyn L, Heen AF, Vernooij RW, Siemieniuk RA, et al. Prostate cancer screening with prostate-specific antigen (PSA) test: A clinical practice guideline. BMJ (Online) 2018;362:k3581.

6. Thompson IM, Ankerst DP, Chi C, Goodman PJ, Tangen CM, Lucia MS, et al. Assessing prostate cancer risk: Results from the prostate cancer prevention trial. J Natl Cancer Inst 2006;98(8):529-34.

7. Sartor O, de Bono JS. Metastatic prostate cancer. N Engl J Med 2018;378(7):645-57.

8. D’Amico AV, Whittington R, Malkowicz SB, Wu YH, Chen $M$, Art M, et al. Combination of the preoperative PSA level, biopsy Gleason score, percentage of positive biopsies, and MRI T-stage to predict early PSA failure in men with clinically localized prostate cancer. Urology 2000;55(4):572-7.

9. Nebbioso A, Tambaro FB, Dell'Aversana C, Altucci L. Cancer epigenetics: Moving forward. PLoS Genet 2018;14(6):e1007362.

10. Yegnasubramanian S, de Marzo AM, Nelson WG. Prostate cancer epigenetics: From basic mechanisms to clinical implications. Cold Spring Harb Perspect Med 2019;9(4):a030445.

11. Wu Y, Sarkissyan M, Vadgama JV. Epigenetics in breast and prostate cancer. Methods Mol Biol 2015;1238:42566.

12. Cooper CS, Foster CS. Concepts of epigenetics in prostate cancer development. 2009;100(2):240-5.

13. Schulz WA, Hatina J. Epigenetics of prostate cancer: Beyond DNA methylation. J Cell Mol Med. 2006;10(1):100-25.

14. Cillo C, Faiella A, Cantile M, Boncinelli E. Homeobox genes and cancer. Exp Cell Res 1999;248(1):1-9.

15. Vega-Benedetti AF, Loi E, Moi L, Blois S, Fadda A, Antonelli $\mathrm{M}$, et al. Clustered protocadherins methylation alterations in cancer. Clin Epigenet 2019;11(1):100.

16. Strand SH, Orntoft TF, Sorensen KD. Prognostic DNA methylation markers for prostate cancer. Int J Mol Sci 2014;15(9):16544-76.

17. Jerónimo C, Bastian PJ, Bjartell A, Carbone GM, Catto JW, Clark SJ, et al. Epigenetics in prostate cancer: Biologic and clinical relevance. Eur Urol. 2011;60(4):75366.

18. Su J, Huang YH, Cui X, Wang X, Zhang X, Lei Y, et al. Homeobox oncogene activation by pan-cancer DNA hypermethylation. Genome Biol 2018;19(1):108.

19. Abate-Shen C. Deregulated homeobox gene expression in cancer: Cause or consequence? Nat Rev Cancer 
2002;2(10):777-85.

20. Kron KJ, Liu L, Pethe VV, Demetrashvili N, Nesbitt ME, Trachtenberg J, et al. DNA methylation of HOXD3 as a marker of prostate cancer progression. Lab Investig 2010;90(7):1060-7.

21. Liu L, Kron KJ, Pethe VV, Demetrashvili N, Nesbitt ME, Trachtenberg J, et al. Association of tissue promoter methylation levels of APC, TGF 32 , HOXD3 and RASSF1A with prostate cancer progression. Int J Cancer 2011;129(10):2454-62.

22. Savio AJ, Kamdar S, Jeyapala R, Olkhov-Mitsel E, Cuizon C, Finelli A, et al. Methylation markers in prostate biopsies are prognosticators for late biochemical recurrence and therapy after surgery in prostate cancer patients. J Mol Diagn 2020;22(1):30-9.

23. Pancho A, Aerts T, Mitsogiannis MD, Seuntjens E. Protocadherins at the crossroad of signaling pathways. Front Mol Neurosci 2020;13:117.

24. Giefing M, Zemke N, Brauze D, Kostrzewska-Poczekaj M, Luczak M, Szaumkessel M, et al. High resolution ArrayCGH and expression profiling identifies PTPRD and PCDH17/PCH68 as tumor suppressor gene candidates in laryngeal squamous cell carcinoma. Genes Chromosomes Cancer 2011;50(3):154-66.

25. Costa VL, Henrique R, Danielsen SA, Eknaes M, Patrício P, Morais A, et al. TCF21 and PCDH17 methylation: An innovative panel of biomarkers for a simultaneous detection of urological cancers. Epigenetics 2011;6(9):1120-30.

26. Wang XB, Lin YL, Li ZG, Ma JH, Li J, Ma JG. Protocadherin 17 promoter methylation in tumour tissue from patients with bladder transitional cell carcinoma. J Int Med Res 2014;42(2):292-9.

27. Hu X, Sui X, Li L, Huang X, Rong R, Su X, et al. Protocadherin 17 acts as a tumour suppressor inducing tumour cell apoptosis and autophagy, and is frequently methylated in gastric and colorectal cancers. J Pathol 2013;229(1):62-73.

28. Lin YL, Xie PG, Wang L, Ma JG. Aberrant methylation of protocadherin 17 and its clinical significance in patients with prostate cancer after radical prostatectomy. Med Sci Monit 2014;20:1376-82. 